\title{
Improving medical care and prevention in adults with congenital heart disease-reflections on a global problem-part I: development of congenital cardiology, epidemiology, clinical aspects, heart failure, cardiac arrhythmia
}

\author{
Rhoia Neidenbach ${ }^{1}$, Koichiro Niwa ${ }^{2}$, Oeztekin Oto ${ }^{3}$, Erwin Oechslin ${ }^{4}$, Jamil Aboulhosn ${ }^{5}$, David \\ Celermajer $^{6}$, Joerg Schelling ${ }^{7}$, Lars Pieper $^{8}$, Linda Sanftenberg $^{7}$, Renate Oberhoffer, ${ }^{1,9}$, Fokko de Haan ${ }^{10}$, \\ Michael Weyand ${ }^{11}$, Stephan Achenbach ${ }^{12}$, Christian Schlensak ${ }^{13}$, Dirk Lossnitzer ${ }^{14}$, Nicole Nagdyman ${ }^{1}$, \\ Yskert von Kodolitsch $^{15}$, Hans-Carlo Kallfelz ${ }^{16}$, David Pittrow ${ }^{17}$, Ulrike M. M. Bauer ${ }^{18}$, Peter Ewert ${ }^{1}$, \\ Thomas Meinertz ${ }^{15}$, Harald Kaemmerer ${ }^{1}$
}

${ }^{1}$ Department of Pediatric Cardiology and Congenital Heart Disease, German Heart Center Munich, Technical University Munich, Munich, Germany; ${ }^{2}$ Department of Cardiology, Cardiovascular Center, St Luke's International Hospital, Tokyo, Japan; ${ }^{3}$ Dokuz Eylul University Hospital air Esref Cad, Izmir, Turkey; ${ }^{4}$ Toronto Congenital Cardiac Centre for Adults, Peter Munk Cardiac Centre, University Health Network, Toronto General Hospital, and University of Toronto, Toronto, Ontario, Canada; ${ }^{5}$ Ahmanson/UCLA Adult Congenital Heart Disease Center, Los Angeles, USA; ${ }^{6}$ Central Clinical School Heart Research Institute C39 - Royal Prince Alfred Hospital, The University of Sydney, NSW 2006, Australia; ${ }^{7}$ Institute of General Practice and Family Medicine, University Hospital of Ludwig-Maximilians-University Munich, Munich, Germany; ${ }^{8}$ Chair of Behavioral Epidemiology, Institute for Clinical Psychology und Psychotherapy, Technical University Dresden, Dresden, Germany; ${ }^{9}$ Preventive Pediatrics, Technical University Munich, Munich, Germany; ${ }^{10}$ Cardiological Clinic Solingen, Solingen, Germany; ${ }^{11}$ Department of Cardiac Surgery, ${ }^{12}$ Department of Cardiology, University of Erlangen, Erlangen, Germany; ${ }^{13}$ Clinic for Thorax-, Heart- and Vessel Surgery, German Heart Competence Center, Tübingen, Germany; ${ }^{14}$ Medical Clinic I, University Mannheim, Mannheim, Germany; ${ }^{15}$ University Heart Center Hamburg, University Clinic Hamburg-Eppendorf, Hamburg, Germany; ${ }^{16}$ Clinic for Pediatric Cardiology und Intensive medicine, Medical School Hannover, Hannover, Germany; ${ }^{17}$ Institute for Clinical Pharmacology, Medical Faculty, Technical University Carl Gustav Carus, Dresden, Germany; ${ }^{18}$ Competence Network Congenital Heart Defects, Berlin, Germany

Contributions: (I) Conception and design: All authors; (II) Administrative support: All authors; (III) Provision of study materials or patients: All authors; (IV) Collection and assembly of data: All authors; (V) Data analysis and interpretation: All authors; (VI) Manuscript writing: All authors; (VII) Final approval of manuscript: All authors.

Correspondence to: Linda Sanftenberg. Institute of General Practice and Family Medicine, University Hospital of Ludwig-Maximilians-University Munich, Pettenkoferstr. 10, 80336 Munich, Germany. Email: linda.sanftenberg@med.uni-muenchen.de.

\begin{abstract}
Today most patients with congenital heart defects (CHD) survive into adulthood. Unfortunately, despite relevant residua and sequels, follow-up care of adults with congenital heart disease (ACHD) is not performed in specialized and/or certified physicians or centres. Major problems in the long-term course encompass heart failure, cardiac arrhythmias, heart valve disorders, pulmonary vascular disease, infective endocarditis, aortopathy and non-cardiac comorbidities. Many of them manifest themselves differently from acquired heart disease and therapy regimens from general cardiology cannot be transferred directly to CHD. It should be noted that even simple, postoperative heart defects that were until recently considered to be harmless can lead to problems with age, a fact that had not been expected so far. The treatment of ACHD has many special features and requires special expertise. Thereby, it is important that treatment regimens from acquired heart disease are not necessarily transmitted to CHD. While primary care physicians have the important and responsible task to set the course for adequate diagnosis and treatment early and to refer patients to appropriate care in specialized ACHD-facilities, they should actively encourage ACHD to pursue follow-up care in specialized facilities who can provide responsible and advanced advice. This medical update emphasizes the current data on epidemiology, heart failure and cardiac arrhythmia in ACHD.
\end{abstract}


Keywords: Congenital heart defect (CHD); endocarditis; heart failure; primary health care; pulmonary hypertension

Submitted Jun 01, 2018. Accepted for publication Jul 02, 2018.

doi: $10.21037 / \mathrm{cdt} .2018 .10 .15$

View this article at: http://dx.doi.org/10.21037/cdt.2018.10.15

\section{Introduction}

In the near future, preventive medicine measures will be of paramount importance for the care of patients with congenital heart defects (CHD) (1-3).

CHD are the most common isolated inborn organ malformations. Worldwide, 1.35-1.5 million children are born with CHD each year, approximately $45 \%$ of them with moderate or complex, the remaining $55 \%$ with simple heart defects $(4,5)$.

The reported incidence or birth prevalence of CHD largely depends on the study design and the lack of birth registries in many countries, ranging from five to eight per 1,000 live births before the introduction of echocardiography, and from eight to 12 per 1,000 thereafter (6).

With some geographical differences, the incidence of CHD is similar across all countries (6). The total number of annual births of children with CHD is assumed to be approximately 725,000 in Asia, 335,000 in Africa, 108,000 in Europe, 71,000 in North-America, 65,000 in SouthAmerica, and 6,000 in Australia (Figure 1) (6).

\section{Development of congenital cardiology, epidemiology}

Until about $1940,80 \%$ of children with complex CHD died within the first few years of life. Currently more than $90 \%$ of the children reach adult age (7), mainly due to substantial advances in congenital cardiology, cardiac surgery, intensive care, and pharmacotherapy $(8,9)$. According to a large Canadian study not only the mortality of children with CHD decreased notably, but also the age of death has shifted to later in adulthood and there is a transition of a bimodal to a unimodal age distribution at death which resembles the pattern in the general population (10). A prospective, 40-year study from Norway with 7,038 patients also indicated that the mortality of CHD fell significantly between 1971 and 2011 (11). This fact induces a major shift regarding the medical care for patients with CHD, particularly in the developed world (Figure 2), as the number of adults with CHD nowadays exceeds the number of children with CHD (13).

Although mortality of CHD has decreased considerably, morbidity remains substantial which is widely underestimated. It must be recognized that complete "correction" or "repair" of CHD, resulting in permanently normalized cardiac structure and function, normal life expectancy, and lack of requirement for any further treatment, is the exception (14). Thus, despite adequate repair almost all patients with CHD are chronically ill, and many have residua and sequels of the respective cardiac defect requiring specific follow-up and care (15). This is of major concern since specific efforts are necessary to provide adequate care for the affected population. Of note, medical care in specialized centers is able to significantly reduce mortality in children and adults with CHD (16).

"Residua", are anatomical or hemodynamic deviations, remaining from the original cardiovascular malformation prior to the intervention or operation, and which were not treated completely during the procedures. "Sequels", on the other hand, result from the potential side-effects and long-term complications of the specific intervention or operation (17). In this context heart failure, cardiac arrhythmias, heart valve disorders, conduit complications, pulmonary vascular disease, or endocarditis are most relevant. Of major importance is also the arteriopathy encountered in many different CHD as well as monogenetic aortic syndromes, such as Marfan-, Loeys-Dietz- (18), vascular Ehlers-Danlos-Syndrome (19), or familial non-syndromic thoracic aortic aneurysm or dissection (TAAD). Additionally, acquired cardiac and non-cardiac comorbidities can adversely affect the outcome of the CHD. Vice versa course and treatment of comorbidities can be decisively modified by the CHD $(20,21)$.

Moreover, an increasing number of women with CHD want to have children of their own. As the number of pregnant woman with rheumatic heart disease is declining, 


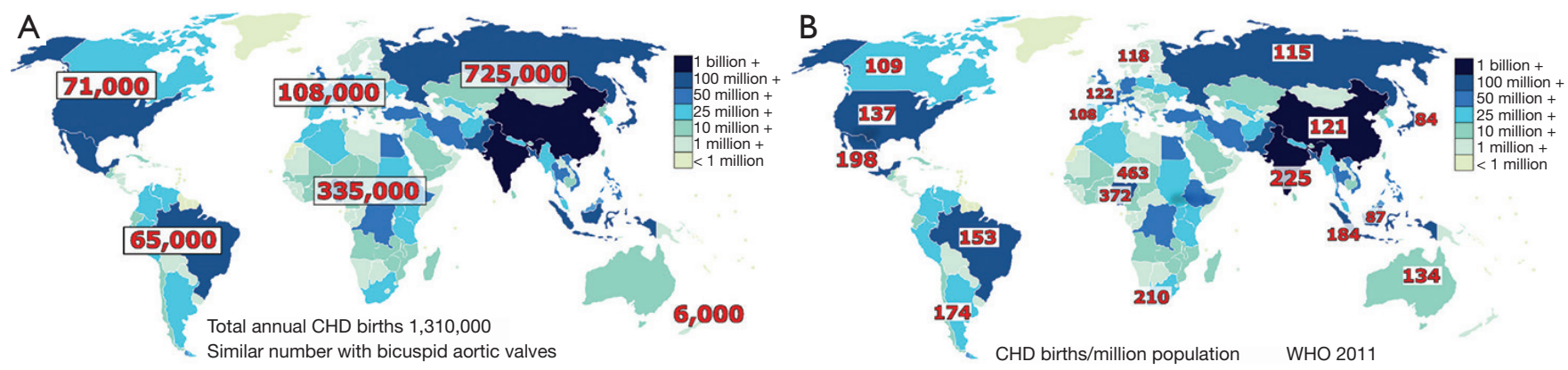

Figure 1 Annual births of children with congenital heart disease. (A) Total annual births of children with CHD by continent. The incidence or birth prevalence of CHD largely depends on the study design (3); (B) number of children born with CHD per million population. The incidence or birth prevalence of CHD largely depends on the study design (3). CHD, congenital heart disease. From Hoffman (6). Reprinted with permission.

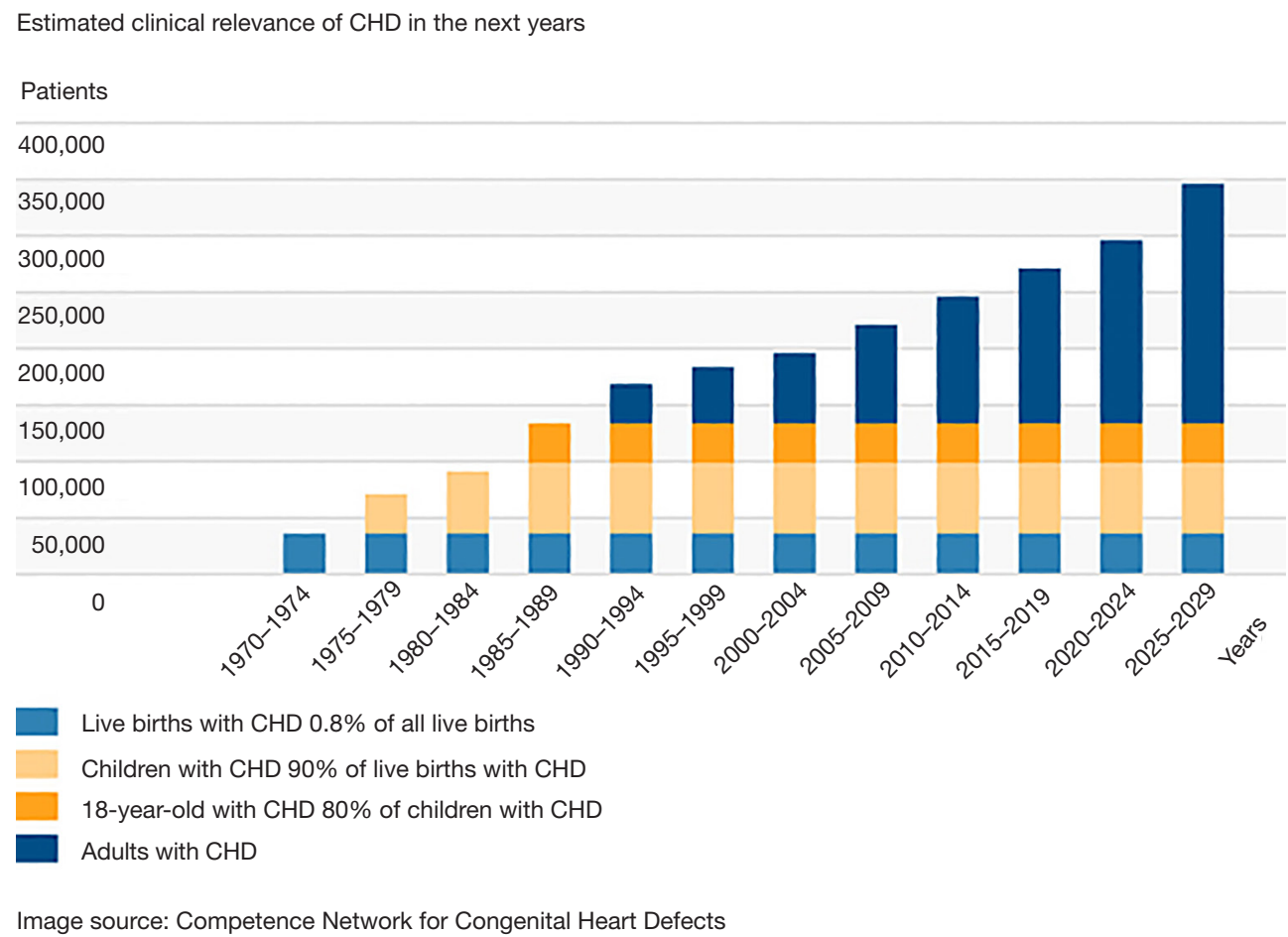

Figure 2 Estimated clinical relevance of CHD in the next years from the German National Register for Congenital Heart Defects (12). CHD, congenital heart disease. Reprinted with permission. Copyright by: Nationales Register für angeborene Herzfehler, 2016 (12).

at least in the developed world, CHD is meanwhile the most common form of heart disease in pregnancy, and a leading cause of maternal morbidity and mortality.

As many CHD-related problems manifest differently from acquired heart disease, established treatment regimens for acquired heart disease can only be applied to a limited extent to CHD $(22,23)$.

\section{Heart failure}

The onset of heart failure is critical with respect to morbidity and mortality of adults with CHD, where heart failure is the cause of death in up to $25 \%$ of patients (24-26), developing both in native CHD as well as after surgical or interventional treatment. The risk of heart failure is particularly high in univentricular hearts (after 
Fontan operation), transposition of the great arteries (TGA) and a subaortic right ventricle (e.g., after Mustard/Senning procedure; in congenitally corrected transposition of the great arteries (cc-TGA), as well as in severe pulmonary artery disease due to shunt lesions (e.g., EisenmengerSyndrome). Patients with severe valvular heart disease, e.g., after repair of Fallot's tetralogy (TOF), with atrioventricular (AV) septal defects or a Shone complex, are also represented in this group.

Current incidence and prevalence data of heart failure in CHD are not reliable, because they derive from different definitions of heart failure. They range from limited exercise capacity, via activation of neurohumoral factors or a reduced ejection fraction to "classical" signs of right or left heart decompensation, as seen in acquired heart disease. Older data describe heart failure in $22 \%$ of cc-TGA, in $32 \%$ after atrial switch operation for TGA, and in $40 \%$ of Fontan patients (27). The reported hospitalization rate for symptomatic heart failure is 1.2/1,000 patient years (26).

The underlying pathophysiological changes are multifactorial and determined by the underlying specific CHD. Decisive mechanisms are hemodynamic factors, such as chronic pressure or volume overload, concomitant cardiac arrhythmias, or the presence and degree of cyanosis or pulmonary vascular disease. Additional factors include the duration and extent of cyanosis before the initial repair of the CHD, the patient age at time of surgery or intervention, the type of intervention, or the mode of intraoperative cardioprotection. Also operative scars and large artificial patches may be other additional factors. Acquired comorbidities gain importance with increasing age, aggravating the natural/unnatural course of the CHD (20). Coronary artery disease, arterial hypertension, peripheral arterial disease, metabolic disorders (e.g., diabetes mellitus, hyperlipidemia), cerebrovascular diseases, chronic obstructive pulmonary disease, myocarditis, or other organ involvement (e.g., liver, kidney) may negatively impact the prognosis and long-term outcome.

Recognition of heart failure in CHD can be tricky and should be known to the treating physician (28). In contrast to acquired heart disease, many patients with CHD do not notice exercise limitations, or do not admit difficulties as they adjust to a lower exercise tolerance since childhood.

Additionally, the diagnosis of heart failure by commonly used parameters (e.g., diameters, volumes, ejection fraction) is often problematic or impossible in CHD, in particular in a morphologically right systemic ventricle. Normal or threshold values for the respective condition may not be defined or deviate from reference values used in general adult cardiology. Examples are the measured diameters or volumes in the univentricular heart after Fontan operation, in TGA after atrial switch procedure, or in cc-TGA.

Consequently, the course of the disease should be assessed by intra-individual comparison, i.e., each patient serves as his/her own control. Longitudinal monitoring is of paramount importance in individual patient care because of the lack of standard reference values in CHD. This emphasizes the need to concentrate follow-up in specialized centres that are able to provide continuous high-level care.

At the same time, there is a considerable uncertainty regarding therapeutic measures in CHD $(29,30)$. Due to the substantial heterogeneity of CHD available data are usually based on small patient cohorts. In contrast to general cardiology, large data from controlled studies are scarce, as the presence of CHD is typically an exclusion criterion in heart failure studies.

If patients with CHD have signs and symptoms of heart failure, it is critical to recognize or exclude causal changes in hemodynamics, potentially be amenable to interventional or surgical treatment. This is increasingly true in the presence of coronary artery disease or other organ diseases, like renal or liver disease.

Drug therapy of heart failure has to consider all specific aspects of the particular CHD (Figures 3,4). Treatment aims include an improvement of clinical symptoms, a better resilience and a better health related quality of life. In addition, the long-term life expectancy should be improved.

For systolic failure of a morphologically left systemic ventricle, preferably renin-angiotensin-aldosteroneinhibitors (RAAI) like angiotensin-converting-enzyme inhibitors (ACEI), angiotensin receptor blockers (ARBs), as well as $\beta$-receptor blockers, mineralocorticoid receptor antagonists (e.g., spironolactone, eplerenone) and diuretics (e.g., high-ceiling diuretics, thiazides, metolazone) are preferably used (31). The role of digitalis glycosides is controversial in CHD, but should not be neglected in severe heart failure, particularly if associated with atrial fibrillation (32-34).

For heart failure with preserved systolic function ("Heart Failure with preserved Ejection Fraction", HFpEF) there is hardly any data for CHD. Treatment of systolic heart failure in patients with a morphologically right subaortic ventricle (e.g., TGA after atrial switch procedure, cc-TGA, univentricular hearts of right ventricular type) is even more complex (35). Data and experiences for treating a failing morphologic left ventricle cannot be adopted here. Insufficient, sometimes even 

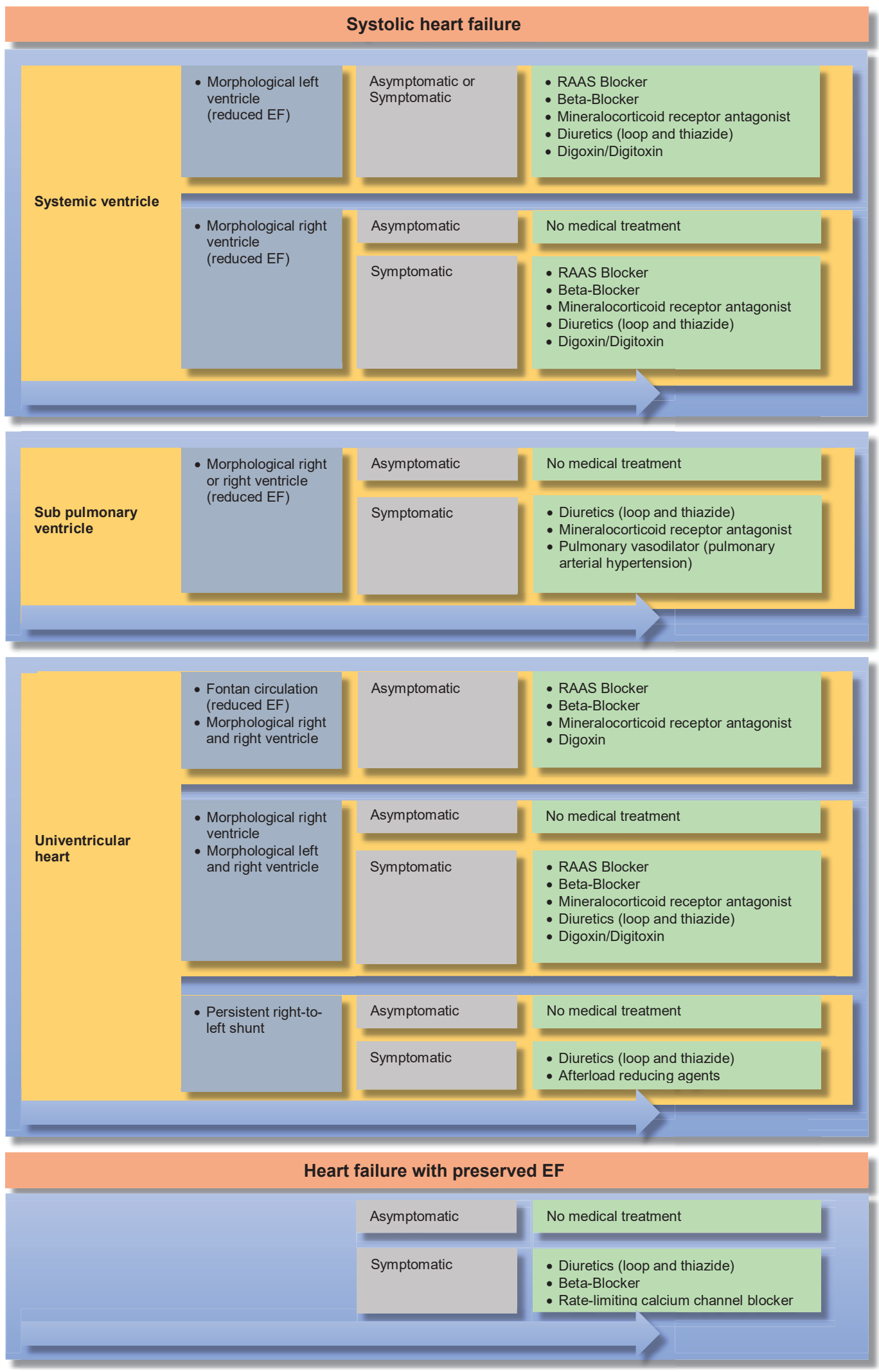

Figure 3 Medical treatment for heart failure related to intrinsic myocardial dysfunction. From Budts et al. (30). Adapted with permission. 


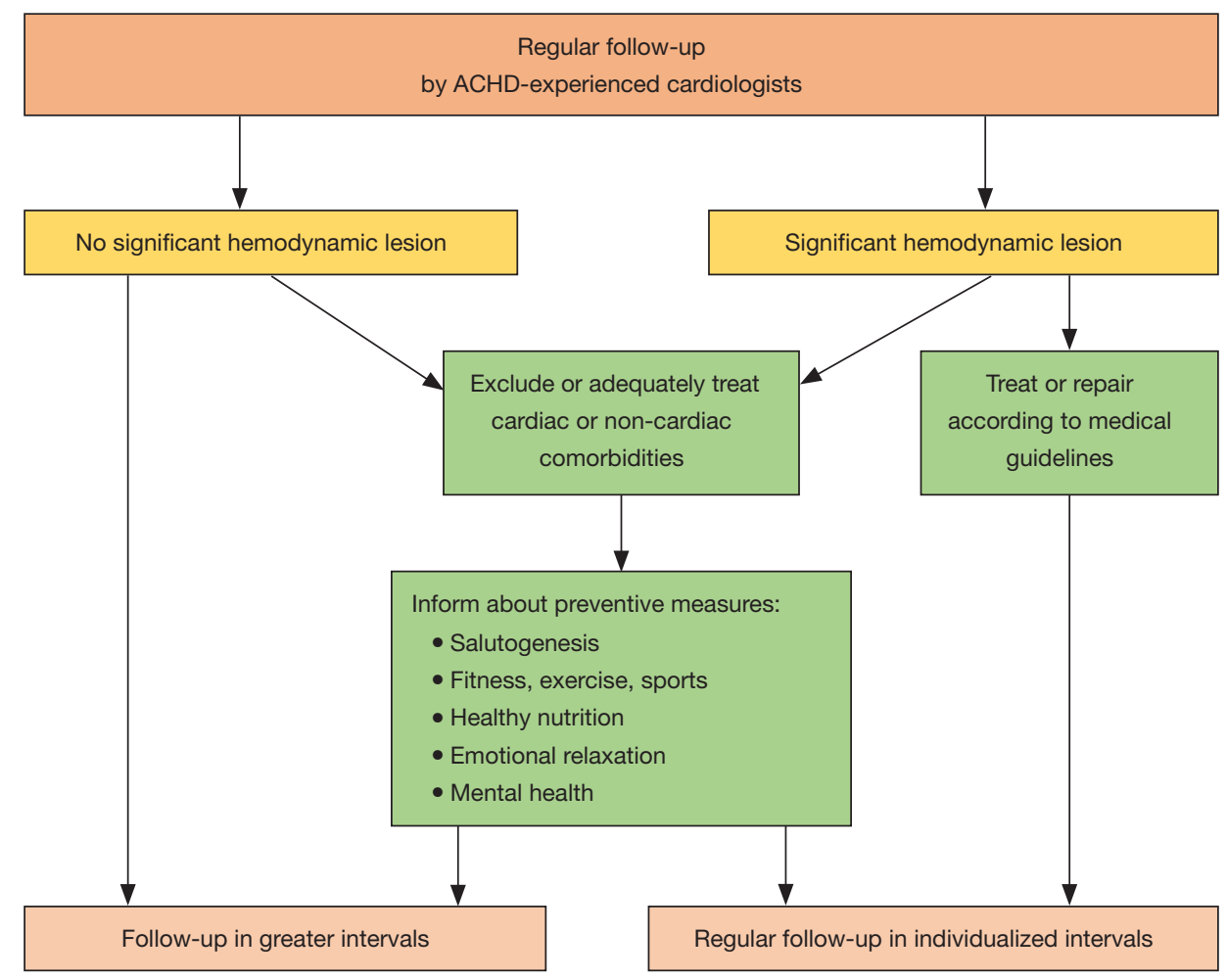

Figure 4 Management algorithms for the care of adults with congenital heart disease.

contradictory trial data are available (36,37), particularly for the use of ACEI, AT-blockers, $\beta$-receptor blockers, or other medications. Again, most of these trial data result from small, uncontrolled studies in heterogeneous cohorts with a short follow-up (38-40).

A special issue is the therapy of patients with Fontan circulation, in which diastolic and systolic heart failure, as well as chronotropic incompetence and an increase of pulmonary vascular resistance may develop. The correct evaluation and assessment of blood flow in Fontan patients and the resulting therapeutic consequences are complex and require detailed pathophysiological knowledge. While not enough data are available for the use of ACEI or ATB, the use of phosphodiesterase type 5 inhibitors (PDE-5-I) or endothelin receptor antagonists (ERA) is discussed (41-43).

As alternative therapies for refractory heart failure in CHD, cardiac resynchronization therapy (CRT), ventricular assist device (VAD), artificial hearts, or heart-(HTX) or combined heart-lung-transplantation (HLTX) are available $(21,44)$.

For cardiac resynchronization therapy (CRT) specific anatomical and physiological aspects of the underlying CHD must be taken into account. In patients with a subaortic left ventricle, international guidelines are often used for decision making, but in complex CHD (e.g., univentricular hearts, subaortic right ventricle) identification of ideal candidates and indications are difficult since randomized, prospective data are lacking. Device implantation can be challenging in complex anatomy and after several previous operations. As strong data about the long-term outcome are not available, the clinical value is not clear at this point $(21,45)$.

The use of a VAD for CHD is predominantly discussed in single case reports or smaller series, for example as "bridging to transplant" for patients with a failing subaortic right systemic ventricle or in Fontan patients (46-50).

Heart transplantation (HTX) or combined heartlung transplantation (HLTX) are feasible options for CHD-patients, although the lack of donors and technical challenges make this last resource unattractive for many centers (51). Particularly complex CHD patients are often disadvantaged on the heart transplant waiting list. Despite the young age of CHD patients, the donor hearts are frequently allocated to patients with a conventional cardiac anatomy because of technical challenges. In any case, peculiarities of anatomy and pathophysiology of 
each individual condition (e.g., anomalies of the veins, arteries and pulmonary arteries, type and number of previous operations, intrathoracic adhesions, collaterals, and immunologic diseases, status after previous blood transfusions) have to be taken into account. Finally, the transplantation listing criteria for patients with CHD are not clearly defined, but they may well differ from those of other cardiac disorders, and may require a clearer definition (52).

After transplantation, the early mortality appears to be high, whereas the ten-year prognosis is better for patients with CHD than for non-CHD patients $(21,53)$. However, condition-specific results are also to be taken into account (e.g., transplantation in Fontan circulation and protein losing enteropathy). Because of concomitant renal or hepatic diseases, combined organ transplants have been performed in individual cases (54).

In summary, assessment and treatment of heart failure in CHD is challenging and requires special expertise as recommendations for acquired heart disease cannot be applied uncritically (55). Therefore, CHD patients are best served in a dedicated ACHD heart failure clinic.

\section{Cardiac arrhythmia}

Patients with CHD have an intrinsic risk for tachy- or bradyarrhythmias, which are the most frequent causes of death in long-term care (56-59). These arrhythmias are often caused by myocardial fibrosis, postoperative intracardiac scars or worsening of the hemodynamic situation. Particularly affected are patients with native or earlier surgically repaired atrial septal defect, tetralogy of Fallot, TGA after atrial redirection, univentricular hearts after Fontan operation or Ebstein's anomaly.

Sinus node dysfunction and AV blocks are often associated with former surgical procedures at atrial or ventricular level, generating an injury to the conduction system. Postoperatively, areas with abnormal electrophysiologic properties may serve as slow conducting pathways within a macro-reentrant circuit or may be the source of focal atrial tachycardia.

Supraventricular tachycardias often include intra-atrial reentry tachycardias and atrial flutter. In contrast, atrial fibrillation is comparatively rare in younger adults with CHD, sometimes seen in congenital mitral valve anomalies, after shunt-operations or by degeneration from atrial tachycardia or flutter. Atrial fibrillation is not so rare in elderly patients with CHD.
The most important ventricular tachyarrhythmias include mono- and polymorphic ventricular tachycardia and ventricular fibrillation. These arrhythmias are particularly found after ventriculotomy, after patch closure of VSD, e.g., after Fallot-repair or after Rastelli-type operation in TGA.

The primary treatment objectives of any type of cardiac arrhythmias comprise the improvement of the subjective condition, the reduction of morbidity, the maintenance of ventricular function, and an improvement of prognosis by preventing sudden cardiac death (60). The risk assessment for the occurrence of sudden cardiac death is difficult in CHD and has to be considered individually.

Of note, supraventricular tachycardia may be also poorly tolerated in CHD, especially in complex cases (e.g., after atrial redirection, in Fontan circulation, in cyanotic CHD, in Eisenmenger syndrome) and, other than in normal hearts, can result in cardiac decompensation or even death.

To detect and document important arrhythmias, the "event recorder" has become increasingly important. They can either be small, portable ECG devices, which can be used in subjectively noticed events or arrhythmias. A different type can be implanted subcutaneously and can be read out like a pacemaker. Smartphone applications will gain importance in the future, particularly for "atrial fibrillation screening".

Treatment options for arrhythmias in CHD include pharmacotherapy, ablation procedures, and the implantation of pacemakers or defibrillators $(61,62)$. In supraventricular arrhythmias, drug therapy is preferably used to maintain sinus rhythm, to prevent recurrence of arrhythmias or to control the heart rate if sinus rhythm cannot be restored. However, whenever possible, a causal electrophysiological treatment is preferred for supraventricular as well as ventricular arrhythmias. Thereafter, a supplementary pharmacological treatment is often required, mostly using amiodarone.

"Device" therapy with pacemakers or implantable defibrillators is becoming increasingly important as the patient age increases (63). The individual anatomy of the underlying CHD is decisive in order to ensure the optimal and safe lead placement. Epicardial or subcutaneous implantation techniques are used especially in complex or cyanotic CHD. However, it should be noted that the incidence of inappropriate shocks is high. Many ACHD have SVT as well as VT and since discrimination can be difficult, programming should refer on the side of caution. It is not uncommon that $\mathrm{ACHD}$ with frequent inappropriate 
shocks develop a disabling post-traumatic stress disorder.

In patients with CHD appropriate oral anticoagulation is highly relevant, as the risk for thromboembolism may be even higher than in patients with acquired heart disease (60). Current scoring systems (e.g., CHA2DS2VASc score and HAS-BLED score) provide only a rough estimate and are not validated for ACHD! Furthermore, new, direct oral anticoagulants of the Non-vitamin-K antagonist (NOAC/DOAC) are insufficiently validated in CHD patients (63).

Detailed recommendations on the treatment of ACHD were published as a separate guideline in 2014 (63). Particularly the treatment of complex CHD, due to the special nature of the defect, should be referred to a specialized ACHD-clinic for a full hemodynamic and electrophysiologic work-up and to implement an individually tailored management plan.

In conclusion, although today most patients with CHD survive into adulthood, many of them have relevant residua and sequels, and deeply need an experienced follow-up care in specialized and/or certified physicians or centres. Thereby, it is important that treatment regimens from acquired heart disease are not necessarily transmitted to CHD. Even simple, postoperative heart defects that were until recently considered to be harmless can lead to problems with age, a fact that had not been expected so far. Moreover, the awareness of ACHD problems must be increased to close actual supply gaps.

In the field of CHD primary and secondary medical prevention will henceforth become increasingly important in order to reduce the burden of disease as well as the socioeconomic burden and costs.

\section{Acknowledgements}

The paper is dedicated to the memory of Dr. Joseph Kayle PERLOFF, Los Angeles, founder of the new specialty of Cardiology -'Adults with congenital heart disease'-who passed away on August 18, 2014.

Funding: This work was supported by the German Heart Foundation ("Deutsche Herzstiftung e.V.") (grant number F-30-15), the patient organization "Herzkind e. V.", Actelion Pharmaceuticals Germany GmbH (grant number MED-2015-495) and the German health care insurance AOK-Bayern.

\section{Footnote}

Conflicts of Interest: $\mathrm{R}$ Neidenbach received research grants ("Unrestricted educational grant") from Actelion
Pharmaceuticals Deutschland GmbH and from the German Heart Foundation ("Deutsche Herzstiftung e.V.) and the patient organization "Herzkind e. V.". H Kaemmerer received fees and/or travel expenses for consulting activities and/or lectures from the following companies within the last 3 years: Actelion, Pfizer, Bayer-Healthcare, BristolMyers Squibb. D Pittrow has received speaker fees or honoraria for consultations from Actelion, Bayer, Genzyme, Boehringer Ingelheim, Novartis, MSD, and Pfizer. E Oechslin currently holds the "Bitove Family Professorship for Adult Congenital Heart Disease". Other authors have no conflicts of interest to declare.

\section{References}

1. Stout KK, Daniels CJ, Aboulhosn JA, et al. 2018 AHA/ ACC Guideline for the Management of Adults With Congenital Heart Disease: Executive Summary: A Report of the American College of Cardiology/American Heart Association Task Force on Clinical Practice Guidelines. J Am Coll Cardiol 2018. [Epub ahead of print].

2. Lui GK, Saidi A, Bhatt AB, et al. Diagnosis and Management of Noncardiac Complications in Adults With Congenital Heart Disease: A Scientific Statement From the American Heart Association. Circulation 2017;136:e348-92.

3. Neidenbach RC, Lummert E, Vigl M, et al. Non-cardiac comorbidities in adults with inherited and congenital heart disease: report from a single center experience of more than 800 consecutive patients. Cardiovasc Diagn Ther 2018;8:423-31.

4. Schmaltz A, Bauer U. Adults with congenital heart disease: treatment and medical problems. Herz 2013;38:639-51; quiz 652-4.

5. van der Linde D, Konings EE, Slager MA, et al. Birth prevalence of congenital heart disease worldwide: a systematic review and meta-analysis. J Am Coll Cardiol 2011;58:2241-7.

6. Hoffman JI. The global burden of congenital heart disease. Cardiovasc J Afr 2013;24:141-5.

7. Kaemmerer H, Meisner H, Hess J, et al. Surgical treatment of patent ductus arteriosus: a new historical perspective. Am J Cardiol 2004;94:1153-54.

8. Kaemmerer H, Lummert E, Engelhardt A, et al. Angeborene Herzfehler: Zur Nachsorge ermuntern. Der Hausarzt 2014;17:50-4.

9. Deutscher Herzbericht 2017, 2018, Frankfurt am Main, 
Herausgeber: Deutsche Herzstiftung. Germany 167-200.

10. Khairy P, Ionescu-Ittu R, Mackie AS, et al. Changing mortality in congenital heart disease. J Am Coll Cardiol 2010;56:1149-57.

11. Erikssen G, Liestøl K, Seem E, et al. Achievements in congenital heart defect surgery: A prospective, 40 year study of 7038 patients. Circulation 2015;131:337-46; discussion 346.

12. Nationales Register für angeborene Herzfehler, Germany. 2016. Available online: http://www.kompetenznetz-ahf.de/ en/research/register-biobank/

13. Marelli AJ, Ionescu-Ittu R, Mackie AS, et al. Lifetime prevalence of congenital heart disease in the general population from 2000 to 2010. Circulation 2014;130:749-56.

14. Stark J. Do we really correct congenital heart defects? J Thorac Cardiovasc Surg 1989;97:1-9.

15. Perloff JK, Warnes CA. Challenges posed by adults with repaired congenital heart disease. Circulation 2001;103:2637-43.

16. Mylotte D, Pilote L, Ionescu-Ittu R, et al. Specialized adult congenital heart disease care: the impact of policy on mortality. Circulation 2014;129:1804-12.

17. Warnes CA, Williams RG, Bashore TM, et al. ACC/ AHA 2008 guidelines for the management of adults with congenital heart disease. Circulation 2008;118:e714-833.

18. Von Kodolitsch Y, De Backer J, Schüler H, et al. Perspectives on the revised Ghent criteria for the diagnosis of Marfan syndrome. Appl Clin Genet 2015;8:137.

19. Murdoch JL, Walker BA, Halpern BL, et al. Life expectancy and causes of death in the Marfan syndrome. N Engl J Med 1972;286:804-8.

20. Lummert E, Hauser M, Vigl M, et al. Noncardiac comorbidities of congenital heart disease in adults. Am J Cardiol 2014;113:S109.

21. Ministeri M, Alonso-Gonzalez R, Swan L, et al. Common long-term complications of adult congenital heart disease: avoid falling in a HEAP. Expert Rev Cardiovasc Ther 2016;14:445-62.

22. Kaemmerer H, Hess J. Adult patients with congenital heart abnormalities: present and future. Dtsch Med Wochenschr 2005;130:97-101.

23. Kaemmerer H, Hess J. Congenital heart disease. Transition from adolescence to adulthood. Internist (Berl) 2009;50:1221-2, 1224-7.

24. Engelings CC, Helm PC, Abdul-Khaliq H, et al. Cause of death in adults with congenital heart disease-an analysis of the German National Register for Congenital Heart
Defects. Int J Cardiol 2016;211:31-6.

25. Verheugt CL, Uiterwaal CS, van der Velde ET, et al. Mortality in adult congenital heart disease. Eur Heart J 2010;31:1220-9.

26. Zomer A, Vaartjes I, Van Der Velde E, et al. Heart failure admissions in adults with congenital heart disease; risk factors and prognosis. Int J Cardiol 2013;168:2487-93.

27. Piran S, Veldtman G, Siu S, et al. Heart failure and ventricular dysfunction in patients with single or systemic right ventricles. Circulation 2002;105:1189-94.

28. Faccini A, Micheletti A, Negura D, et al. Heart failure in grown-up congenital heart disease. Minerva Cardioangiol 2018;66:329-36.

29. Van De Bruaene A, Meier L, Droogne W, et al. Management of acute heart failure in adult patients with congenital heart disease. Heart Fail Rev 2018;23:1-14.

30. Budts W, Roos-Hesselink J, Rädle-Hurst T, et al. Treatment of heart failure in adult congenital heart disease: a position paper of the Working Group of GrownUp Congenital Heart Disease and the Heart Failure Association of the European Society of Cardiology. Eur Heart J 2016;37:1419-27.

31. Ponikowski P, Voors AA, Anker SD, et al. 2016 ESC Guidelines for the diagnosis and treatment of acute and chronic heart failure: The Task Force for the diagnosis and treatment of acute and chronic heart failure of the European Society of Cardiology (ESC) Developed with the special contribution of the Heart Failure Association (HFA) of the ESC. Eur Heart J 2016;37:2129-200.

32. Lindenfeld J, Keller K, Campbell DN, et al. Improved systemic ventricular function after carvedilol administration in a patient with congenitally corrected transposition of the great arteries. J Heart Lung Transplant 2003;22:198-201.

33. Vamos M, Erath JW, Hohnloser SH. Digoxin-associated mortality: a systematic review and meta-analysis of the literature. Eur Heart J 2015;36:1831-8.

34. Ziff OJ, Kotecha D. Digoxin: The good and the bad. Trends Cardiovasc Med 2016;26:585-95.

35. Brida M, Diller GP, Gatzoulis MA. Systemic Right Ventricle in Adults With Congenital Heart Disease: Anatomic and Phenotypic Spectrum and Current Approach to Management. Circulation 2018;137:508-18.

36. Therrien J, Provost Y, Harrison J, et al. Effect of angiotensin receptor blockade on systemic right ventricular function and size: a small, randomized, placebo-controlled study. Int J Cardiol 2008;129:187-92.

37. van der Bom T, Winter MM, Bouma BJ, et al. Effect 
of valsartan on systemic right ventricular function: a double-blind, randomized, placebo-controlled pilot trial. Circulation 2013;127:322-30.

38. Hechter SJ, Fredriksen PM, Liu P, et al. Angiotensinconverting enzyme inhibitors in adults after the Mustard procedure. Am J Cardiol 2001;87:660-3.

39. Lester SJ, McElhinney DB, Viloria E, et al. Effects of losartan in patients with a systemically functioning morphologic right ventricle after atrial repair of transposition of the great arteries. Am J Cardiol 2001;88:1314-6.

40. Robinson B, Heise C, Moore J, et al. Afterload reduction therapy in patients following intraatrial baffle operation for transposition of the great arteries. Pediatr Cardiol 2002;23:618-23.

41. Aboulhosn J, Child JS. The adult with a Fontan operation. Curr Cardiol Rep 2007;9:331-5.

42. Derk G, Houser L, Miner P, et al. Efficacy of endothelin blockade in adults with Fontan physiology. Congenit Heart Dis 2015;10:E11-6.

43. Dore A, Houde C, Chan KL, et al. Angiotensin receptor blockade and exercise capacity in adults with systemic right ventricles: a multicenter, randomized, placebo-controlled clinical trial. Circulation 2005;112:2411-6.

44. Koyak Z, de Groot JR, Krimly A, et al. Cardiac resynchronization therapy in adults with congenital heart disease. Europace 2018;20:315-22.

45. Triedman JK, Newburger JW. Trends in Congenital Heart Disease: The Next Decade. Circulation 2016;133:2716-33.

46. Di Molfetta A, Amodeo A, Gagliardi MG, et al. Hemodynamic effects of ventricular assist device implantation on Norwood, Glenn, and Fontan circulation: a simulation study. Artif Organs 2016;40:34-42.

47. Halaweish I, Ohye R, Si M. Berlin heart ventricular assist device as a long term bridge to transplantation in a Fontan patient with failing single ventricle. Pediatr Transplant 2015;19:E193-5.

48. Peng E, O’Sullivan JJ, Griselli M, et al. Durable ventricular assist device support for failing systemic morphologic right ventricle: early results. Ann Thorac Surg 2014;98:2122-9.

49. Cedars A, Vanderpluym C, Koehl D, et al. An Interagency Registry for Mechanically Assisted Circulatory Support (INTERMACS) analysis of hospitalization, functional status, and mortality after mechanical circulatory support in adults with congenital heart disease. J Heart Lung Transplant 2018;37:619-30.

50. VanderPluym CJ, Cedars A, Eghtesady P, et al. Outcomes following implantation of mechanical circulatory support in adults with congenital heart disease: an analysis of the Interagency Registry for Mechanically Assisted Circulatory Support (INTERMACS). J Heart Lung Transplant 2018;37:89-99.

51. Bryant R, Morales D. Overview of adult congenital heart transplants. Ann Cardiothorac Surg 2018;7:143.

52. Davies RR, Russo MJ, Yang J, et al. Listing and Transplanting Adults With Congenital Heart Disease Clinical Perspective. Circulation 2011;123:759-67.

53. Karamlou T, Diggs BS, Person T, et al. National practice patterns for management of adult congenital heart disease: operation by pediatric heart surgeons decreases in-hospital death. Circulation 2008;118:2345-52.

54. Robinson JA, Driscoll DJ, O'Leary PW, et al., editors. Cardiac and multiorgan transplantation for end-stage congenital heart disease. Mayo Clinic proceedings, Elsevier, 2014.

55. Lal S, Kotchetkova I, Cao J, et al. Heart failure admissions and poor subsequent outcomes in adults with congenital heart disease. Eur J Heart Fail 2018;20:812-5.

56. Nieminen HP, Jokinen EV, Sairanen HI. Causes of late deaths after pediatric cardiac surgery: a population-based study. J Am Coll Cardiol 2007;50:1263-71.

57. Oechslin EN, Harrison DA, Connelly MS, et al. Mode of death in adults with congenital heart disease. Am J Cardiol 2000;86:1111-6.

58. Warnes CA. The adult with congenital heart disease: born to be bad? J Am Coll Cardiol 2005;46:1-8.

59. Moore B, Yu C, Kotchetkova I, et al. Incidence and clinical characteristics of sudden cardiac death in adult congenital heart disease. Int J Cardiol 2018;254:101-6.

60. Pujol C, Niesert A-C, Engelhardt A, et al. Usefulness of direct oral anticoagulants in adult congenital heart disease. Am J Cardiol 2016;117:450-5.

61. Hernández-Madrid A, Paul T, Abrams D, et al. Arrhythmias in congenital heart disease: a position paper of the European Heart Rhythm Association (EHRA), Association for European Paediatric and Congenital Cardiology (AEPC), and the European Society of Cardiology (ESC) Working Group on Grown-up Congenital heart disease, endorsed by HRS, PACES, APHRS, and SOLAECE. Europace 2018. [Epub ahead of print].

62. Khairy P, Van Hare GF, Balaji S, et al. PACES/HRS expert consensus statement on the recognition and management of arrhythmias in adult congenital heart disease: developed in partnership between the Pediatric and Congenital Electrophysiology Society (PACES) and the Heart Rhythm 
Society (HRS). Endorsed by the governing bodies of PACES, HRS, the American College of Cardiology (ACC), the American Heart Association (AHA), the European Heart Rhythm Association (EHRA), the Canadian Heart Rhythm Society (CHRS), and the International Society for Adult Congenital Heart Disease (ISACHD). Can J Cardiol 2014;30:e1-63.

63. Vehmeijer JT, Mulder BJ, de Groot JR. Current state of risk stratification for sudden cardiac death in adults with congenital heart disease. Anatol J Cardiol 2018. [Epub ahead of print].
Cite this article as: Neidenbach R, Niwa K, Oto O, Oechslin E, Aboulhosn J, Celermajer D, Schelling J, Pieper L, Sanftenberg L, Oberhoffer R, de Haan F, Weyand M, Achenbach S, Schlensak C, Lossnitzer D, Nagdyman N, von Kodolitsch Y, Kallfelz HC, Pittrow D, Bauer UM, Ewert P, Meinertz T, Kaemmerer H. Improving medical care and prevention in adults with congenital heart disease-reflections on a global problem-part I: development of congenital cardiology, epidemiology, clinical aspects, heart failure, cardiac arrhythmia. Cardiovasc Diagn Ther 2018;8(6):705-715. doi: 10.21037/ cdt.2018.10.15 